\title{
STRATEGI OPERASI UNTUK MEMPRODUKSI PRODUK BARU PADA PT INKOASKU
}

\author{
OPERATION STRATEGIES TO PRODUCE NEW PRODUCTS AT PT INKOASKU
}

\author{
Nindya Yohana Debora*)1, Erlinda Nusron Yunus*) \\ *)Sekolah Tinggi Manajemen PPM \\ Jl. Menteng Raya No. 9-19, Menteng, Jakarta, Indonesia
}

\begin{abstract}
This study aims to formulate the mission, objectives and strategy of operation or manufacturing for an automotive component factory that will produce a new product. The scope of this research is a case study at PT Inkoasku. Structured interviews were conducted with managers at PT Inkoasku related to customers and suppliers (external analysis) and quality, process, inventory, capacity, and supply chain (internal analysis). The questions are aimed at knowing the current external and internal operating conditions when only producing wheels and further needs when starting to produce disc' as a new product. In addition to interviews, observations were also conducted on the operating system at PT Inkoasku. The results of external analysis show that the winner of orders from PT Inkoasku's operating system is price, while quality and delivery are order qualifications. Therefore, the operating strategies that can be applied include: choosing the type of batch process in running production, adding lean-six sigma in the quality system, automating the machine that will be used to produce disc', optimizing the Material Requirement Planning (MRP) system and the min-max policy. in inventory management as well as mapping the procurement of goods and services and implementing Vendor-Managed Inventory (VMI) as a supply chain strategy.
\end{abstract}

Keywords: operation management, operation strategy, manufacturing strategy, automotive component industry, QPICS

\begin{abstract}
Abstrak: Penelitian ini bertujuan merumuskan misi, tujuan dan strategi operasi atau strategi manufaktur bagi pabrik komponen otomotif yang akan memproduksi produk baru. Ruang lingkup penelitian ini adalah studi kasus pada PT Inkoasku. Wawancara terstruktur dilakukan dengan manajer-manajer yang ada di PT Inkoasku terkait dengan pelanggan dan pemasok (analisis eksternal) dan quality, process, inventory, capacity, dan supply chain (analisis internal). Pertanyaan-pertanyaan tersebut ditujukan untuk mengetahui kondisi eksternal dan internal operasi saat ini ketika hanya memproduksi wheel dan kebutuhan selanjutnya ketika mulai memproduksi disc' sebagai produk baru. Selain wawancara terstruktur pengamatan juga dilakukan terhadap sistem operasi di PT Inkoasku. Hasil analisis eksternal menunjukkan bahwa order winner dari sistem operasi PT Inkoasku adalah harga sedangkan kualitas dan delivery merupakan order qualifier. Oleh karena itu, strategi operasi yang dapat diterapkan antara lain: memilih tipe proses batch dalam menjalankan produksi, menambahkan lean-six sigma dalam sistem kualitas, mengotomatisasi mesin yang akan digunakan untuk memproduksi disc', mengoptimalisasi sistem Material Requirements Planning (MRP) dan min-max policy dalam pengelolaan persediaan serta melakukan pemetaan pengadaan barang-jasa dan menerapkan Vendor Managed Inventory sebagai strategi rantai pasok.
\end{abstract}

Kata kunci: manajemen operasi, strategi operasi, strategi manufaktur, industri komponen otomotif, rantai pasok, QPICS

${ }^{1}$ Corresponding author:

Email: erl@ppm-manajemen.ac.id 


\section{PENDAHULUAN}

Dalam memacu pertumbuhan ekonomi nasional, industri otomotif merupakan salah satu sektor andalan. Hal ini dapat terlihat dari kontribusi industri otomotif yang cukup signifikan terhadap produk domestik bruto (PDB), khususnya PDB non migas yaitu sebesar 3,98 persen pada tahun 2019 (Gaikindo, 2020). Selain itu Indonesia merupakan salah satu pasar otomotif terbesar di ASEAN dengan penjualan mobil sebesar 1,1 juta unit per tahun atau 33 persen dari total penjualan mobil di ASEAN selama beberapa tahun terakhir (Gaikindo, 2019). Berdasarkan peta jalan Making Indonesia 4.0, industri otomotif termasuk satu dari lima sektor manufaktur yang mendapat prioritas pengembangan dari pemerintah, terutama dalam kesiapan memasuki era industri 4.0 (Kemenperin, 2019). Pemerintah berharap industri otomotifIndonesia mampu menghasilkan produk yang berdaya saing global sehingga dapat meningkatkan ekspor nasional. Kementrian Perindustrian(Kemenperin) mengungkapkan bahwa pengembangan produktivitas dan daya saing industri otomotif harus sejalan dengan pengembangan industri komponen. Hal ini disebabkan karena industri alat-alat kendaraan bermotor merupakan bagian dari rantai pasok bagi Original Equipment Manufacturer (OEM) industri otomotif. Industri komponen berpeluang untuk terus berkembang seiring dengan pertumbuhan industri otomotif.

Namun, adanya pandemi COVID-19 pada tahun 2020 menyebabkan penurunan penjualan mobil di Indonesia yang cukup drastis. Berdasarkan data Gabungan Industri Kendaraan Bermotor Indonesia (Gaikindo), penjualan mobil secara nasional di Indonesia mencapai angka 532.027 unit, menurun sebesar 48,35\% jika dibandingkan tahun sebelumnya. Turunnya volume pasar mobil berdampak pada industri komponen yang masih berorientasi untuk memenuhi kebutuhan industri perakitan kendaraan bermotor atau OEM. Penurunan penjualan mobil mengakibatkan turunnya penjualan perusahaan-perusahaan yang memproduksi komponen bagi kendaraan bermotor seperti yang dialami oleh PT Inkoasku.

PT Inkoasku merupakan perusahaan yang memproduksi salah satu komponen otomotif, yaitu wheel (pelek) yang terbuat dari baja. PT Inkoasku memiliki dua pabrik yang berbeda lokasi, yaitu di Sunter dan Karawang. Namun kapasitas produksi kedua pabrik tersebut jauh melebihi rata-rata penjualan. PT Inkoasku mampu memproduksi sebanyak 4,8 juta wheel per tahun sedangkan penjualan rata-rata per tahun sejak 2017 hingga 2019 hanya 2 juta wheel. Kapasitas yang hanya digunakan setengahnya menunjukkan bahwa PT Inkoasku memiliki utilisasi yang rendah. Hal tersebut mendorong PT Inkoasku untuk mencoba mengembangkan bisnis baru dengan memanfaatkan kapasitas berlebih tersebut. Produk baru dikembangkan sesuai dengan fasilitas dan mesin yang dimiliki. Dengan adanya pegembangan produk baru tersebut diharapkan adanya peningkatan utilisasi dan optimalisasi fasilitas PT Inkoasku.

PT Inkoasku mendapat permintaan untuk memproduksi komponen otomotif selain wheel, yaitu disc' sehingga PT Inkoasku berencana untuk memasuki bisnis baru, yaitu memproduksi disc' tanpa meninggalkan bisnis yang lama, yaitu manufaktur steel wheel. Memproduksi komponen otomotif selain wheel merupakan hal yang baru bagi PT Inkoasku. Terdapat beberapa isu yang akan memengaruhi sistem operasi PT Inkoasku ketika memproduksi wheel dan disc'. Isu-isu tersebut antara lain: (1) Meskipun wheel dan disc' menggunakan bahan baku yang sama tetapi kedua produk tersebut memiliki proses produksi yang berbeda karena tidak semua mesin yang ada saat ini akan digunakan untuk memproduksi disc'. Mesin yang ada saat ini yang digunakan untuk memproduksi wheel antara lain mesin stamping, welding, assembly, dan painting sedangkan untuk memproduksi disc' mesin yang digunakan hanyalah mesin stamping dan painting. (2) Terdapat perbedaan spesifikasi atau kualitas antara produk disc' dan produk wheel. (3) Adanya perbedaan kebutuhan packaging, baik secara kuantitas dan kualitas (4) Kebutuhan akan penyesuaian sistem sediaan, penjadwalan produksi dan distribusi ketika angka produksi meningkat. Hal tersebut mendorong PT. Inkoasku agar merancang strategi operasi atau strategi manufaktur untuk beberapa tahun ke depan. Selain itu strategi manufaktur merupakan faktor penting untuk meningkatkan kinerja operasi (Arana-Solares et al. 2019). Strategi operasi atau strategi manufaktur yang dikembangkan harus sejalan dengan misi dan tujuan fungsional operasi PT. Inkoasku.

Penelitian ini menggunakan pendekatan studi kasus untuk menganalisis keadaan saat ini dan merancang strategi dengan tiga tahapan, yaitu tahapan input, tahapan penyelarasan dan tahapan penentuan strategi. Pada tahap input dilakukan analisis eksternal, internal, misi dan tujuan operasi (Schroeder dan Goldstein, 2021). Pada tahap penyelarasan dilakukan analisis gap antara keadaan saat ini dengan kebutuhan yang akan datang. Strategi operasi dapat disusun berdasarkan data yang 
didapatkan pada tahap input dan penyelarasan. Studi kasus pada penelitian ini dilakukan pada PT Inkoasku yang memproduksi komponen otomotif wheel untuk berbagai pabrik pabrik perakit mobil. Pada tahun 2020 PT Inkoasku berencana memproduksi produk baru, yaitu disc'.

Operasi merupakan salah satu fungsi di perusahaan yang bertanggung jawab untuk mengelola sumber daya yang dibutuhkan agar dapat menghasilkan barang dan jasa. Strategi operasi adalah rencana yang menetapkan desain dan penggunaan sumber daya untuk mendukung strategi bisnis, termasuk lokasi, ukuran dan jenis fasilitas yang tersedia; keterampilan dan bakat pekerja yang dibutuhkan; penggunaan teknologi, proses khusus yang dibutuhkan, peralatan dan metode kendali mutu (Schroeder dan Goldstein, 2021). Peran strategi operasi adalah menyediakan rencana untuk fungsi operasi agar dapat memanfaatkan sumber daya dengan sebaik mungkin. Strategi operasi harus selaras dengan strategi bisnis perusahaan dan mendukung perusahaan untuk mencapai rencana jangka panjang (Okoshi et al. 2019). Menurut Schroeder dan Goldstein (2021), terdapat empat elemen inti dari strategi operasi yaitu misi fungsional operasi, tujuan fungsional operasi, keputusan strategis operasi dan kompetensi khusus.

Menurut Schroeder dan Goldstein (2021, misi operasi harus memberikan dukungan untuk strategi bisnis perusahaan dan menunjukkan kompetensi atau kapabilitas khusus operasi perusahaan, sedangkan tujuan fungsional operasi harus diturunkan dari misi operasi dan merupakan pernyataan kembali dari misi fungsional operasi yang terukur dan memberikan keunggulan kompetitif bagi perusahaan agar dapat memenangkan pasar. Secara umum terdapat empat tujuan operasi (Schroeder dan Goldstein, 2021), yaitu cost, quality, delivery dan flexibility. Dari keempat tujuan fungsional operasi diatas, perusahaan perlu memberikan fokus hanya pada beberapa prioritas dalam menjalankan operasinya yang dirumuskan ke dalam order qualifier dan order winner (Hill, 1995). Order qualifier adalah competitive priorities yang harus dipenuhi perusahaan jika ingin berbisnis di pasar tertentu sedangkan order winner adalah competitive priorities yang membantu perusahaan untuk memenangkan pesanan di pasar (Hill, 1995).

Setelah menetapkan misi dan tujuan operasi, keputusan strategis operasi dapat ditentukan. Strategi operasi menentukan bagaimana tujuan operasi akan dicapai.
Pola keputusan strategis operasi harus mencakup lima bidang utama, yaitu proses, kualitas kapasitas, sediaan dan rantai pasok atau yang biasa disebut QPICS (Quality, Process, Inventory, Capacity, Supply Chain). Perhatian yang cermat pada lima bidang keputusan tersebut adalah kunci keberhasilan pengelolaan operasi dan rantai pasokan.

Beberapa penelitian sebelumnya mengenai strategi operasi dan strategi manufaktur antara lain mengenai teori dan definisi strategi manufaktur serta perkembangannya (Kulkarni et al. 2019; Chatha et al. 2018), strategi operasi untuk pengiriman yang efektif pada penawaran produk jasa industri yang terintegrasi (Datta dan Roy, 2011), strategi operasi manajemen fasilitas di pusat perbelanjaan (Chotipanich dan Issarasak, 2017), proses dan kinerja strategi operasi pada industri manufaktur pakaian (Jagoda dan Kiridena, 2015), strategi operasiproduksi kosmetik (Dwiyanti et al. 2017) strategi manufaktur berkelanjutan dan ramah lingkungan (Xie dan Han, 2020; Macchi et al. 2020; Ocampo, 2019) dan model keselarasan strategi operasi dan strategi bisnis pada industri di Iran (Shavarini et al. 2013).

Adapun beberapa penelitian mengenai strategi operasi dan strategi manufaktur pada industri otomotif juga telah dilakukan sebelumnya antara lain strategi operasi pabrik perakitan mesin industri otomotif di Brazil (Filho et al. 2015), dimensi lingkungan dalam konteks strategi operasi produsen otomotif wilayah ABC São Paulo (Scur dan Heinz, 2016), strategi operasi untuk menjaga daya saing sebuah perusahaan otomotif di Eropa (Koch et al. 2015), kemampuan manufaktur, strategi manufaktur dan kinerja produsen komponen otomotif Indonesia (Nurcahyo dan Wibowo, 2015), strategi manufaktur berkelanjutan pada produksi mobil tenaga surya (Reinhardt et al. 2017), pemodelan kerangka untuk mengukur kinerja dari strategi manufaktur pada perusahaan yang memproduksi mesin untuk kendaraan berat (Adane dan Nicolescu, 2018), strategi industri kecil menengah komponen otomotif (Rinaldy et al. 2020) dan daya saing rantai pasokan industri manufaktur komponen otomotif di India (Joshi et al. 2013). Kebaruan yang ditawarkan oleh penelitian ini adalah dirumuskannya suatu strategi baru yang sesuai dengan kebutuhan mitra rantai pasok seperti pelanggan dan pemasok serta sesuai dengan kapabilitas internal yang saat ini dimiliki oleh PT Inkoasku. Terlebih lagi, diharapkan melalui strategi yang dihasilkan dari penelitian ini diharapkan PT Inkoasku dapat tetap memiliki daya saing pada masa pandemi COVID-19 dan meningkatkakan pendapatannya. 
Penelitian ini bertujuan (1) menganalisis kondisi eksternal operasi PT Inkoasku sehingga dapat diketahui kebutuhan pemasok dan pelanggan, (2) menganalisis kondisi internal operasi PT Inkoasku sehingga dapat diketahui sistem operasi yang berjalan saat ini, (3) menetapkan misi dan tujuan fungsional operasi PT Inkoasku, (4) merumuskan strategi operasi PT Inkoasku dalam memproduksi wheel dan disc'. Oleh karena itu hasil yang diharapkan dari penelitian ini adalah rancangan strategi operasi PT Inkoasku dalam memproduksi produk baru berdasarkan analisis eksternal dan internal operasi. Rancangan strategi operasi disusun menggunakan framework menurut Schroeder dan Goldstein (2021) yang terdiri dari misi dan tujuan serta keputusan strategis operasi.

\section{METODE PENELITIAN}

Penelitian ini merupakan penelitian studi kasus dengan menggunakan desain penelitian cross sectional dan metode kualitatif deskriptif digunakan dalam penelitian ini. Penelitian dilakukan di pabrik PT Inkoasku yang berada di Karawang, Jawa Barat. Pengumpulan data dilakukan sejak bulan Maret hingga Mei 2021. Data yang dikumpulkan dalam penelitian ini adalah data primer dan data sekunder. Wawancara dan observasi dilakukan untuk mendapatkan data primer sedangkan studi dokumen dilakukan untuk mengumpulkan data sekunder. Wawancara dilakukan untuk mengetahui strategi dan keputusan terkait operasi yang sudah dijalankan sebelumnya. Wawancara dilakukan secara terstruktur kepada beberapa narasumber seperti pihak manajemen, kepala divisi, kepala departemen dan supervisor terkait operasi, produksi, engineering, marketing, quality, inventory dan purchasing. Observasi dilakukan dengan melakukan pengamatan lapangan yaitu melihat aktivitas, kegiatan dan lingkungan kerja perusahaan. Studi dokumen dilakukan terhadap dokumen internal perusahaan untuk mengetahui kondisi dan situasi awal perusahaan dan artikel untuk mengetahui kebutuhan industri sehingga selanjutnya dapat menjadi masukan dan data dalam pengembangan strategi dan implementasinya.

Data wawancara, observasi dan studi dokumen tersebut kemudian dianalisis dengan data reduction, data display, penggambaran dan verifikasi serta penarikan kesimpulan. Metode analisis ini digunakan untuk menunjang penelitian ini yang bersifat kualitatif deskriptif sehingga data-data yang didapatkan merupakan fakta atau bukti yang valid dan konsisten sehingga didapatkan kesimpulan yang kredibel untuk menjawab rumusan masalah. Selain itu berdasarkan data yang telah diperoleh tersebut akan dilakukan analisis gap terhadap dua keadaan yaitu keadaan saat ini (sebelum meproduksi disc') dan keadaan yang akan datang (ketika akan memproduksi disc') untuk menyusun strategi operasi bagi PT Inkoasku.

Kerangka pemikiran penelitian dapat dilihat pada Gambar 1. Penelitian diawali dengan melakukan tahap input, yaitu analisis eksternal, internal, misi dan tujuan operasi saat ini. Analisis tersebut dilakukan untuk dapat mengidentifikasi kebutuhan dan harapan dari pelanggan dan pemasok serta mengevaluasi sistem operasi yang ada saat ini. Berdasarkan hasil identifikasi dan evaluasi tersebut, misi dan tujuan operasi dapat ditetapkan serta kesenjangan antara sistem operasi saat ini (keadaan ketika hanya memproduksi wheel) dan kebutuhan sistem operasi yang akan datang (keadaan ketika memproduksi wheel dan disc' secara bersamaan) dapat diketahui. Hal tersebut merupakan acuan dalam menyusun strategi operasi PT Inkoasku dalam memproduksi wheel dan disc'.

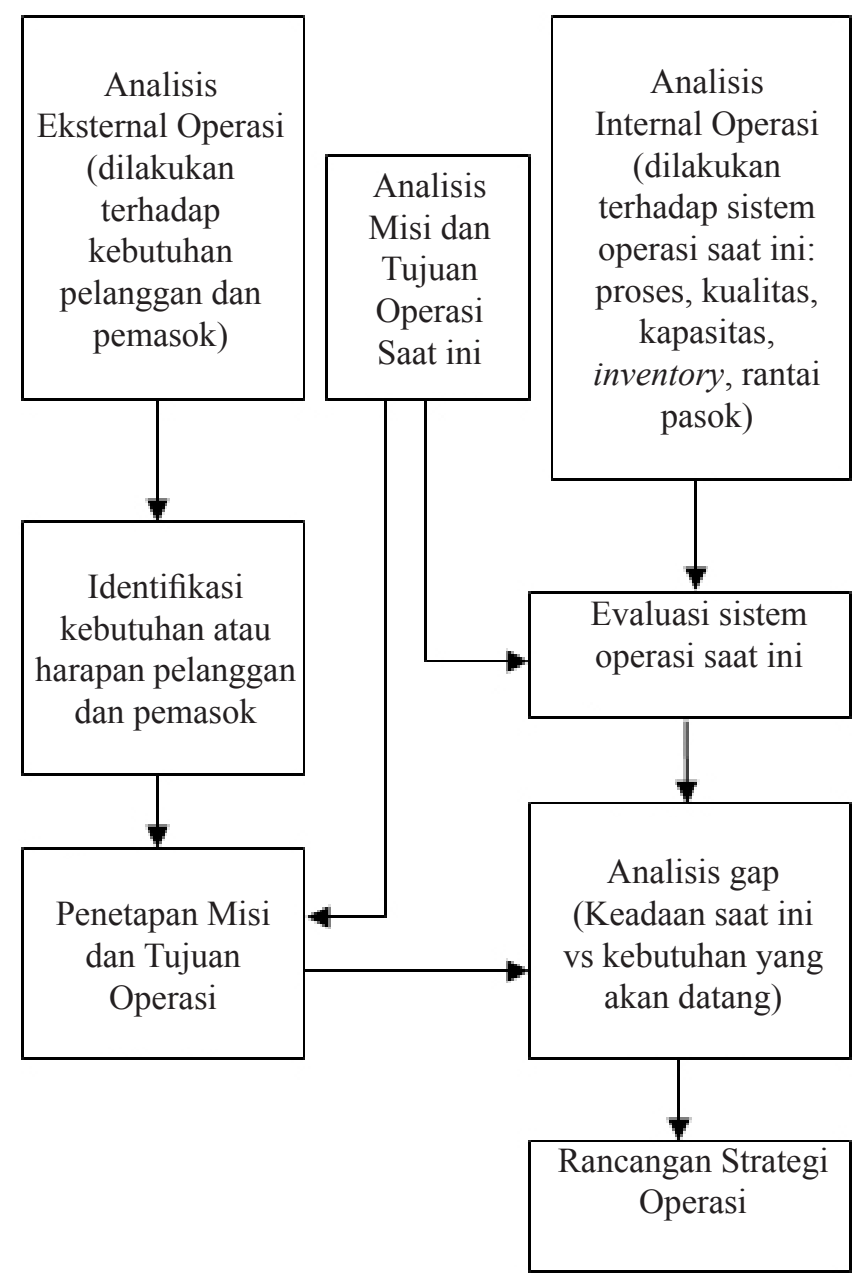

Gambar 1. Kerangka pemikiran penelitian 


\section{HASIL}

\section{Analisis eksternal PT Inkoasku}

Analisis eksternal dilakukan terhadap pelanggan dan pemasok yang dapat dilihat pada Tabel 1. Berdasarkan hasil analisis terhadap pelanggan diketahui bahwa aspek kualitas, delivery dan biaya merupakan hal yang dianggap penting dalam industri otomotif dan komponennya. Pabrik perakitan kendaraan bermotor melaksanakan produksi kendaraan sesuai dengan ketentuan dan arahan teknis dari pemegang merk kendaraan dan menerapkan manufaktur Just In Time (JIT) sehingga aspek kualitas dan delivery menjadi hal yang diharapkan pelanggan. Ketika aspek pengiriman dan pemenuhan terhadap spesifikasi telah dapat terpenuhi maka pelanggan akan memilih pemasok yang dapat menjual produk dengan harga lebih rendah sehingga dapat mengurangi biaya produksi pelanggan. Berdasarkan hasil analisis terhadap pemasok, diketahui bahwa aspek harga dan hubungan dengan pemasok merupakan hal yang penting. Harga yang kompetitif diharapkan oleh pemasok karena kompleksistas pemenuhan bahan baku yang tinggi. Selain itu pemasok juga mengharapkan adanya hubungan yang baik karena adanya kebutuhan transparansi dalam mitra rantai pasok dimana industri otomotif OEM terdapat kebutuhan untuk mengetahui masing-masing entitas pada rantai pasok agar dapat dilakukan penelusuran hingga tier 2 dan tier 3 ketika terdapat masalah kualitas pada produk akhir. Selanjutnya kontrak jangka panjang juga dibutuhkan untuk menjaga kelangsungan bisnis kedua belah pihak.

\section{Analisis internal operasi PT Inkoasku}

Analisis internal operasi PT Inkoasku dilakukan terhadap misi dan tujuan operasi serta sistem operasi yang meliputi lima aspek, yaitu proses, kualitas kapasitas, sediaan dan rantai pasok. Analisis internal dilakukan untuk mengetahui keadaan PT Inkoasku ketika hanya memproduksi wheel. Dalam menetapkan misi operasinya PT Inkoasku menyadari bahwa memberikan layanan terlalu jauh melebihi ekspektasi pelanggan akan menimbulkan biaya yang lebih besar. Aspek keselamatan kerja para pegawai juga menjadi hal yang penting bagi PT Inkoasku dalam menjalankan kegiatan operasinya. Keselamatan kerja menunjukkan bahwa proses telah dijalankan dengan baik dan sesuai dengan prosedur. Tingginya angka kecelakaan kerja juga akan berdampak pada biaya.
Tujuan operasi dirumuskan ke dalamempat aspek, yaitu kualitas, delivery, biaya dan fleksibilitas, (Schroeder dan Goldstein, 2021; Nurcahyo dan Wibowo, 2015; Joshi et al. 2013). Tabel 2 menunjukkan empat aspek tujuan operasi PT Inkoasku. Aspek kualitas menjadi tolak ukur utama PT Inkoasku dalam menjalankan operasinya. Dari keempat tujuan operasi tersebut PT Inkoasku perlu menyusun prioritas yang akan dirumuskan ke dalam order qualifier dan order winner (Schroeder dan Goldstein, 2021; Hill, 1995). Order winner dan order qualifier juga bisa disebut sebagai keunggulan kompetitif atau competitive priorities.

Untuk menganalisis sistem proses saat ini dilakukan pemilihan proses atau proses profiling menggunakan framework yang dikemukakan oleh Hill (1995). Hill (1995) mengkategorikan proses menjadi lima tipe, yaitu project, jobbing, batch, line, dan continuous processing. Berdasarkan process profiling yang telah dilakukan, dapat diketahui bahwa jenis proses yang diterapkan oleh PT Inkoasku saat ini adalah line. Hal ini bisa dilihat dari standardisasi produk, rendahnya tingkat pengenalan produk baru, volume produksi yang tinggi dan menggunakan teknologi yang khusus serta dedicated sehingga proses menjadi tidak fleksibel. Tipe proses line yang dijalankan oleh PT Inkoasku semakin terlihat melalui analisis flow proses produksi produk wheel yang terlihat pada Gambar 2 dengan aliran garis yang bercetak tebal. Ketika memproduksi wheel, semua work center digunakan dan secara berurutan.

Namun ketika PT Inkoasku akan memproduksi wheel dan disc' secara bersamaan maka akan ada pergeseran dari karakteristik proses line menjadi karakteristik proses batch karena untuk menambah disc' sebagai produk yang akan diproduksi maka PT Inkoasku membutuhkan teknologi yang lebih universal. Selain itu volume produksi akan menjadi lebih bervariasi sehingga PT Inkoasku perlu menawarkan fleksibilitas proses yang cukup tinggi. Pergeseran tersebut terlihat jelas pada perbedaan flow proses produksi wheel dan disc' yang terlihat pada Gambar 2 dimana ketika memproduksi disc' tidak semua work center dilalui. Ketika memproduksi wheel mesin yang digunakan adalah stamping, welding, assembly dan painting sedangkan ketika memproduksi disc' yang digunakan hanyalah mesin stamping dan painting. Perbedaan atau pergeseran tersebut akan menjadi gap yang harus diselesaikan agar dapat tercapainya misi dan tujuan fungsional operasi yang telah ditetapkan. 
Tabel 1. Harapan pelanggan dan pemasok PT Inkoasku

Pelanggan

Pabrik komponen dapat menghasilkan produk sesuai dengan spesifikasi yang telah ditetapkan (aspek kualitas)

Pabrik komponen dapat mengirimkan produk tepat waktu dan tepat jumlah (aspek delivery)

Pelanggan akan memilih pabrik komponen dengan harga produk yang lebih rendah (aspek biaya)

Pemasok

Pemasok mengharapkan harga yang kompetitif karena kompleksitas permintaan bahan baku yang tinggi

Pemasok mendapatkan transparansi mitra rantai pasok

Pemasok mengharapkan kontrak jangka panjang

Tabel 2. Tujuan operasi PT Inkoasku

\begin{tabular}{ll}
\hline Kualitas & $\begin{array}{l}\text { Kualitas produk ditentukan dengan seberapa mampu PT Inkoasku menghasilkan produk sesuai dengan } \\
\text { desain, spesifikasi dan persyaratan yang telah ditetapkan oleh pelanggan. }\end{array}$ \\
Delivery & PT Inkoasku harus memenuhi pesanan dengan tepat waktu dan tepat jumlah. \\
Biaya & $\begin{array}{l}\text { Pelanggan akan mencari pemasok dengan harga yang kompetitif sehingga PT Inkoasku terus berusaha } \\
\text { menjadi produsen komponen otomotif berbiaya rendah. }\end{array}$ \\
Fleksibilitas & $\begin{array}{l}\text { Fleksibilitas secara bauran produk merupakan hal yang harus diperhatikan oleh PT Inkoasku karena } \\
\text { produk dibuat dengan kustomisasi yang cukup tinggi }\end{array}$ \\
\hline
\end{tabular}

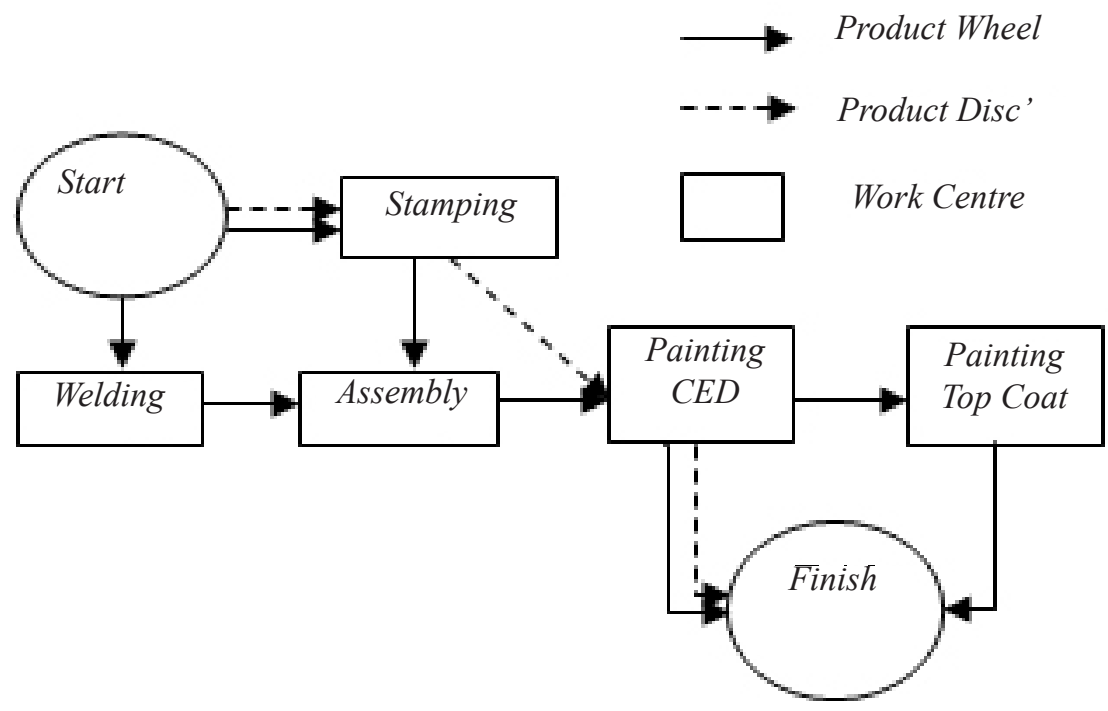

Gambar 2. Flow Produksi Wheel dan Disc'

Analisis sistem kualitas PT Inkoasku saat ini dilakukan menggunakan framework dimensi kualitas barang manufaktur yang dikemukakan oleh Schroeder dan Goldstein (2021). Terdapat empat dimensi, antara lain quality of design, quality of conformance, performance, dan field service. Berdasarkan Tabel 3 diketahui bahwa PT Inkoasku telah menghasilkan produk yang berkualitas karena PT Inkoasku telah mampu memenuhi keempat dimensi tersebut. Untuk menjaga kualitas produk tetap baik, PT Inkoasku juga melakukan perbaikan berkelanjutan ditandai dengan berbagai program-program perbaikan yang didukung oleh setiap karyawan. Hal tersebut dilakukan dengan mengembangkan komite Total Quality Management
(TQM) dalam perusahaan. Komite TQM tersebut akan bertanggung jawab untuk mengawasi dan mengevaluasi program perbaikan yang ada.

Dalam analisis kapasitas, diketahui bahwa PT Inkoasku memiliki dua plant yang berada di Sunter dan Karawang tetapi pada tahun 2021 Plant Sunter akan direlokasi ke Karawang. Plant Karawang mulai beroperasi sejak tahun 2017 dengan berbagai fasilitas yang sudah terotomatisasi sedangkan Plant Sunter masih menggunakan fasilitas yang lebih manual dibandingkan dengan fasilitas yang ada di Karawang. Salah satu yang memengaruhi kapasitas adalah jumlah tenaga kerja yang dibutuhkan. Plant Sunter membutuhkan tenaga 
kerja yang lebih banyak daripada Plant Karawang. Oleh karena itu kebutuhan tenaga kerja akan meningkat karena adanya potensi penambahan jam kerja karena produksi yang meningkat.

PT Inkoasku memiliki kapasitas efektif sebesar $\pm 4,2$ juta wheel per tahun. Namun utilisasi PT Inkoasku pada tahun 2019 tergolong rendah, yaitu masih di bawah $50 \%$ dan bahkan diperparah dengan adanya pandemi COVID-19 yang menyebabkan utilisasi PT Inkoasku menurun pada tahun 2020. Melalui pengembangan produk disc', diharapkan kapasitas work center stamping Plant Sunter dan painting dapat digunakan semaksimal mungkin sehingga utilisasi dapat meningkat. Pada saat membangun plant Karawang. Terdapat empat jenis fasilitas yang dapat dipilih oleh perusahaan dalam menjalankan kegiatan produksinya, antara lain product-focused, market-focused, processfocused, dan general purpose facilities (Schroeder dan Goldstein, 2021). Saat ini PT Inkoasku memilih jenis fasilitas product-focused dimana fasilitas-fasilitas yang digunakan sangat khusus untuk menghasilkan satu tipe produk, yaitu wheel. Oleh karena itu PT Inkoasku perlu mempertimbangkan jenis fasilitas yang akan dipilih ketika produk disc' mengalami perkembangan baik secara teknologi maupun permintaan.

Analisis persediaan PT Inkoasku dilakukan terhadap persediaan bahan baku dan persediaan barang jadi. Berdasarkan jenis permintaan, sediaan dapat dibedakan menjadi dua jenis, yaitu persediaan untuk permintaan independent dan permintaan dependen (Schroeder dan
Goldstein,2021).Pengelompokkan sediaanPTInkoasku dapat dilihat pada Tabel 4. Persediaan bahan baku besi baja dan consumable rutin merupakan sediaan dependen yang kebutuhannya bergantung pada jumlah produk akhir yang akan diproduksi. Sedangkan persediaan consumable tidak rutin merupakan sediaan independen karena kebutuhannya tidak bergantung pada jumlah produk akhir yang akan diproduksi. Seperti pelanggan yang menginformasikan permintaan wheel melalui sistem Pre-Order (PO) kepada PT Inkoasku demikian juga PT Inkoasku melakukan sistem PO kepada para pemasok untuk menginformasikan kebutuhan bahan baku besi baja dan consumable rutin.

Dalam mengelola persediaan bahan baku yang bersifat dependen seperti besi baja dan consumable rutin PT Inkoasku telah menggunakan sistem Material Requirement Planning (MRP). Namun sistem MRP yang diterapkan belum maksimal ditandai dengan tingkat persediaan yang cukup tinggi lebih daripada yang dibutuhkan. Selain sistem MRP yang belum optimal, terdapat beberapa hal lain yang juga perlu dipertimbangkan oleh PT Inkoasku ketika akan meningkatkan jumlah produksi, seperti kapasitas gudang penyimpanan bahan baku dan barang jadi. Sedangkan untuk mengelola persediaan barang jadi PT Inkoasku menerapkan min-max policy dimana PT Inkoasku menetapkan jumlah stok minimum dan maksimum persediaan barang jadi. Jumlah stok minimum dan maksimum ditetapkan berdasarkan data PO dari pelanggan.

Tabel 3. Dimensi kualitas produk PT Inkoasku

\begin{tabular}{ll}
\hline $\begin{array}{l}\text { Quality of design / Kualitas desain } \\
\text { Quality of conformance / Kualitas }\end{array}$ & PT Inkoasku menerjemahkan setiap spesifikasi pelanggan ke dalam product drawing \\
kesesuaian & $\begin{array}{l}\text { PT Inkoasku menghasilkan produk sesuai dengan spesifikasi yang ditetapkan dan } \\
\text { menjaga hasilnya terus konsisten. }\end{array}$ \\
Performance / Kemampuan & $\begin{array}{l}\text { Produk yang dihasilkan oleh PT Inkoasku masih memiliki kinerja yang baik } \\
\text { meskipun melebihi batas durasi waktu yang telah ditetapkan }\end{array}$ \\
& PT Inkoasku memberikan layanan retur, klaim dan garansi \\
\hline
\end{tabular}

Tabel 4. Pengelompokkan sedian PT Inkoasku

\begin{tabular}{lcl}
\hline Persediaan di PT Inkoasku & Tipe sediaan berdasarkan jenis permintaan & Pengelolaan \\
\hline Bahan baku (besi baja) & Dependen & Pre-Order dan MRP \\
$\begin{array}{l}\text { Consumable rutin (cat, chemical, } \\
\text { kawat las) }\end{array}$ & Dependen & Pre-Order dan MRP \\
$\begin{array}{l}\text { Consumable tidak rutin (Spare part } \\
\text { dan pelumas) }\end{array}$ & & \\
Barang jadi & Independen & Pemesanan mengikuti kuantitas \\
\hline
\end{tabular}


Pada analisis rantai pasok diketahui bahwa PT Inkoasku memiliki kurang lebih 100 pemasok baik dalam bentuk barang maupun jasa yang mendukung proses operasinya. Barang dan jasa yang di-outsource oleh PT Inkoasku antara lain besi baja, cat, packaging, jasa pemotongan baja, jasa logistik dan technical assistant. PT Inkoasku telah memiliki Supplier Relationship Management System (SRMS) dimana PT Inkoasku akan melakukan evaluasi dan audit secara berkala terhadap para pemasok. Berdasarkan evaluasi tersebut PT Inkoasku akan menentukan grade bagi setiap supplier. PT Inkoasku juga mengadakan pertemuan secara rutin dengan para pemasok. Dalam pertemuan ini PT Inkoasku menyampaikan kepada para pemasok mengenai isu-isu strategis yang sedang atau akan dihadapi oleh PT Inkoasku.

Prosedur pemilihan pemasok baru juga telah dikembangkan oleh PT Inkoasku. Untuk memastikan pasokannya, PT Inkoasku melakukan kemitraan strategis dengan beberapa pemasok yang memasok bahan baku yang bersifat strategis seperti besi baja, cat dan technical assistant. Menurut Simchi-Levi, et.al (2019) terdapat empat jenis hubungan retailer dan pemasok, yaitu quick response, continuous replenishment, advanced continuous replenishment, dan vendor-managed inventory (VMI). Saat ini strategi hubungan PT Inkoasku dengan para pemasoknya adalah continuous replenishment dimana pemasok menerima data PO dan menggunakan data tersebut untuk mempersiapkan pengiriman pada interval waktu yang telah disepakati sebelumnya untuk mempertahankan tingkat persediaan PT Inkoasku. Pemilihan moda transportasi juga merupakan bagian dalam strategi rantai pasok. Saat ini moda transportasi yang dipilih PT Inkoasku adalah kapal dan truk. Kapal digunakan untuk pengiriman material besi baja yang berasal dari luar Indonesia sedangkan truk digunakan untuk menerima material dari pemasok lokal dan mengirim produk jadi kepada pelanggan.

\section{Penetapan Misi dan Tujuan Operasi PT Inkoasku}

Misi dan tujuan operasi merupakan dua dari empat elemen inti dalam strategi operasi dan perlu ditetapkan di awal agar keputusan-keputusan strategis yang ditetapkan berikutnya selaras dengan strategi bisnis perusahaan (Schroeder dan Goldstein, 2021; Okoshi et al. 2019). Penetapan misi operasi didasari oleh analisis eksternal seperti pelanggan dan pemasok serta analisis internal seperti situasi saat ini dan sumber daya yang dimiliki (Filho et al. 2015). Oleh karena itu misi operasi yang telah ditetapkan oleh PT Inkoasku, yaitu "Menghasilkan produk dengan kualitas yang cukup, sesuai dengan yang dipersyaratkan pelanggan dengan biaya seefisien mungkin serta tetap mengutamakan keselamatan kerja" telah cukup baik dan sesuai dengan kebutuhan eksternal di masa yang akan datang. Misi operasi yang disampaikan oleh PT Inkoasku juga sejalan dengan yang dikemukakan oleh Scur dan Heinz (2016) bahwa keselamatan dan kesehatan kerja dipandang sebagai aspek strategis yang berkontribusi terhadap kinerja kompetitif dari bidang operasi. Namun misi operasi tersebut belum dilaksanakan dengan optimal oleh internal operasi PT Inkoasku sehingga perlu ditetapkan keputusan-keputusan strategis untuk mencapai misi tersebut.

Pada bagian analisis, tujuan operasi terbagi dalam empat aspek. Namun dari pernyataan misi fungsional operasi PT Inkoasku dapat disimpulkan bahwa tujuan operasi yang menjadi aspek prioritas adalah aspek biaya. Oleh karena itu perlu adanya penyusunan prioritas dari keempat aspek tersebut yang dirumuskan ke dalam order qualifier dan order winner (Schroeder dan Goldstein, 2021; Hill, 1995).

Prioritas tujuan operasi PT Inkoasku dapat dilihat pada Tabel 5. Quality dan delivery merupakan order qualifier dari sistem operasi PT Inkoasku karena PT Inkoasku harus mampu memenuhi spesifikasi-spesifikasi yang disyaratkan pelanggan dan memenuhi tenggat waktu yang ditetapkan oleh pelanggan dalam memenuhi pesanan. Jika perusahaan tidak dapat memenuhi kedua aspek tersebut maka perusahaan tidak dapat memasuki persaingan industri otomotif. Aspek kualitas dan delivery merupakan hal yang tidak dapat ditawar dalam industri ini. Cost merupakan order winner dalam sistem operasi PT Inkoasku karena aspek cost merupakan aspek yang masih dapat dinegosiasi dengan pelanggan. Dalam memilih pemasok, cost merupakan aspek yang dapat dipertimbangkan. PT Inkoasku menyadari bahwa kualitas yang baik saja tidak cukup untuk dapat memenangkan persaingan. Pelanggan terkhususnya dalam industri OEM tentunya akan memilih pemasok dengan kualitas baik dan harga yang lebih rendah (Joshi et al. 2013).

Tabel 5. Prioritas Tujuan Operasi PT Inkoasku

\begin{tabular}{cc}
\hline Order Qualifier & Order Winner \\
\hline Quality, Delivery & Cost \\
\hline
\end{tabular}




\section{Strategi Operasi PT Inkoasku dalam Memproduksi Wheel dan Disc'}

Elemen penting selanjutnya dalam merancang strategi operasi adalah penetapan keputusan-keputusan strategis. Keputusan strategis dibuat mengacu pada misi dan prioritas dan tujuan operasi yang telah ditetapkan (Filho et al. 2015). Selain itu beberapa keputusan strategis dibuat sebagai langkah penyesuaian atas gap atau kesenjangan yang terjadi akibat bertambahnya jenis produk yang akan dibuat. Keputusan strategis meliputi lima aspek yaitu proses, kualitas, kapasitas, persediaan dan rantai pasok.

Untuk merespon kesenjangan pada aspek proses, PT Inkoasku dapat memilih batch dalam melaksanakan operasinya. Proses batch dipilih karena perusahaan harus memproduksi produk secara berulang dengan adanya kustomisasi produk, rentang jenis produk yang cukup luas dan volume yang bervariasi. Untuk menangani tugas tersebut, proses dan peralatan yang digunakan harus bersifat umum dan menawarkan tingkat fleksibilitas yang tinggi (Hill, 1995). Hal ini dapat dilakukan dengan memproduksi satu produk yang sama dalam jumlah batch atau kelompok pada satu waktu kemudian dilanjutkan dengan memproduksi jenis produk lainnya yang juga dalam jumlah kuantitas tertentu.

Tantangan dari proses batch adalah aliran produksi yang jumbled akan menghasilkan kompleksitas penjadwalan produksi dan adanya peningkatan persediaan terkhususnya persediaan Work In Process (WIP) (Schroeder dan Goldstein, 2021). Peningkatan persediaan WIP disebabkan oleh adanya antrian material yang menunggu untuk proses selanjutnya. Untuk menghadapi peningkatan persediaan WIP dan proses yang jumbled maka PT Inkoasku perlu mempersiapkan tempat penyimpanan WIP yang sesuai dengan layout dan sistem identifikasi atau pengelompokan WIP agar disc untuk assembly tidak tercampur dengan disc' untuk painting. Pada umumnya operasi batch menggunakan tata letak atau layout berbasis proses. Namun tidak banyaknya jenis proses atau work center yang dibutuhkan saat produksi membuat PT Inkoasku tidak perlu menggunakan tata letak berbasis proses tersebut. Selain itu penggunaan tata letak berbasis proses juga dapat mengganggu aliran produksi wheel yang sudah ada saat ini. Oleh karena itu jenis tata letak yang dapat diadopsi oleh PT Inkoasku adalah cellular manufacturing seperti yang terlihat pada Gambar 3 .
Dalam mempersiapkan sistem kualitas bagi produk baru (disc') dan meningkatkan kualitas dari produk yang sudah ada (wheel) maka PT Inkoasku dapat menerapkan konsep Lean-Six Sigma. Lean dan Six Sigma mempunyai fokus tujuan yang berbeda tetapi dapat saling melengkapi. Dalam jangka panjang peningkatan praktik lean mungkin hanya berdampak kecil pada kinerja bisnis dan perusahaan mungkin perlu menambahkan metode lain untuk tetap meningkatkan kinerja bisnis (Gomez Segura et al. 2020). Sebagai organisasi yang sudah menggunakan lean, PT Inkoasku dapat memanfaatkan penggunaan Six Sigma untuk mengerjakan proyek yang lebih kompleks dan strategis dengan berbasis data yang lebih formal serta menggunakan pemimpin proyek penuh waktu untuk mengurangi cacat dan varian (Ben Ruben et al. 2017). Dengan mengkombinasikan lean dan six sigma PT Inkoasku dapat memenuhi spesifikasi dari pelanggan dengan biaya produksi yang rendah (Swarnakar dan Vinodh, 2016).

Untuk menerapkan Six Sigma PT Inkoasku dapat meninjau tingkat defect menurut konsep Six Sigma terlebih dahulu yang didapatkan saat ini PT Inkoasku baru mencapai level 5 sigma karena jumlah DPMO sebesar 33. Untuk mencapai level six sigma jumlah DPMO harus lebih kecil sama dengan 3,4. Untuk mencapai 6 sigma maka jumlah maksimal defect adalah 10 pcs. Hal lain yang perlu diperhatikan ketika akan menjadikan disc' sebagai produk baru adalah perlu adanya suatu sistem persetujuan mengenai spesifikasi dari produk baru tersebut. PT Inkoasku dan pelanggan harus sepakat mengenai hal-hal yang menjadi spesifikasi. PT Inkoasku dapat menggunakan sistem yang sudah dilakukan selama ini seperti menggunakan request for quotation dan product drawing. Dengan begitu standar kualitas produk disc' dapat ditetapkan.

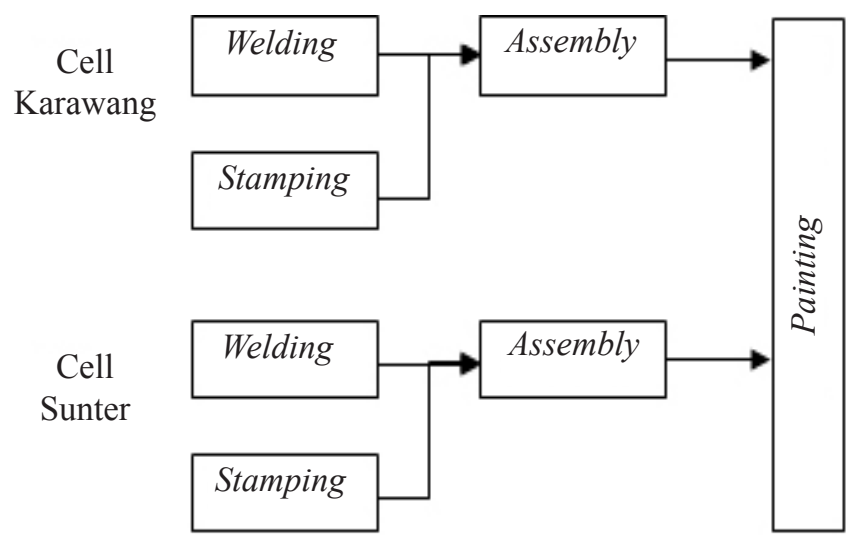

Gambar 3. Cellular Manufacturing PT Inkoasku 
Pada aspek kapasitas, PT Inkoasku perlu mengurangi kebutuhan tenaga kerja pada work center stamping di Plant Sunter. Jumlah produksi yang meningkat akan meningkatkan jam operasional dari fasilitas tersebut sehingga meningkatkan kebutuhan tenaga kerja. Peningkatan jumlah tenaga kerja tersebut akan berbanding lurus pada peningkatan biaya produksi. Oleh karena itu PT Inkoasku dapat berinvestasi pada otomatisasi mesin-mesin work center disc di Plant Sunter. Otomatisasi dapat diterapkan pada area transfer dari satu work station menuju work center lainnya sehingga material dapat berpindah secara otomatis tanpa bantuan dari man power.

Strategi lain yang dapat diterapkan terkait dengan waktu perubahan kapasitas adalah strategi wait and see. Kapasitas produksi yang dimiliki PT Inkoasku saat ini masih sangat besar. Dengan adanya peningkatan jumlah produksi pada beberapa tahun mendatang, utilisasi PT Inkoasku masih belum optimal. Oleh karena itu PT Inkoasku tidak perlu menambah kapasitas produksi dalam tiga tahun mendatang tetapi PT Inkoasku perlu memerhatikan perkembangan permintaan disc' dengan cermat dan menunggu hingga permintaan berkembang sehingga kebutuhan akan penambahan kapasitas menjadi lebih jelas (Schroeder dan Goldstein, 2021). PT Inkoasku juga perlu mempertimbangkan jenis fasilitas yang dibutuhkan untuk jangka panjang. Fasilitas yang berfokus pada proses dapat dipilih mengingat produk yang akan diproduksi bukan hanya wheel tetapi juga komponen otomotif lain yang akan dipasok ke fasilitas atau pabrik lain untuk diproses lebih lanjut (Schroeder dan Goldstein, 2021).

Keputusan strategis persediaan yang pertama adalah mempertahankan persediaan pada tingkat yang rendah baik untuk bahan baku maupun barang jadi. Tingkat persediaan yang rendah dapat mengurangi biaya karena berkurangnya biaya simpan dan meningkatkan perputaran persediaan sehingga cash flow juga akan berputar lebih cepat serta memberikan ruang lebih untuk menyimpan produk lain. Memiliki tingkat persediaan dapat dilakukan dengan cara mengoptimalkan sistem MRP dan lot for lot untuk bahan baku besi baja dan consumable rutin dimana PT Inkoasku hanya memesan sesuai dengan kebutuhan produksi dan mengisi persediaan setiap hari sesuai dengan master schedule produksi yang telah terdokumentasi pada sistem MRP. Tingkat persediaan yang rendah dapat diterapkan oleh PT Inkoasku karena permintaan yang dapat diprediksi melalui sistem PO setiap bulan dan kinerja pemasok yang baik serta dapat diandalkan.

Kebijakan min-max yang ada saat ini telah diterapkan dengan sangat baik oleh PT Inkoasku. Dengan kebijakan tersebut PT Inkoasku dapat mempertahankan persediaan barang jadi pada tingkat yang rendah. Kebijakan ini juga bisa diberlakukan untuk mengelola persediaan barang jadi produk baru disc'. Sedangkan untuk persediaan consumable tidak rutin yang mayoritas merupakan spare part dapat dikelola dengan menerapkan Fixed-Order Quantity Model (Q system) dimana posisi stok akan dipantau setiap adanya transaksi dan barang dipesan dengan kuantitas tetap ketika telah mencapai titik pemesanan ulang (SimchiLevi et al. 2019). Dengan data historis penggunaan spare part, PT Inkoasku dapat menghitung kuantitas pemesanan ekonomis (EOQ) dan menjadikan EOQ sebagai kuantitas pemesanan tetap. Melalui Q system, PT Inkoasku juga dapat memastikan tingkat persediaan yang rendah dengan biaya yang ekonomis.

Hal yang dapat dikembangkan pada aspek rantai pasok adalah strategi pengadaan dan hubungan kemitraan dengan pemasok. Matriks supply Kraljic (1983) seperti pada Gambar 4 dapat digunakan dalam mengembangkan strategi pengadaan dimana PT Inkoasku memetakan barang-barang yang di-outsource berdasarkan risiko pasokan dan dampaknya terhadap profit. Strategi yang tepat untuk barang-barang yang berada pada kuadran strategic items adalah dengan membangun partnership. Membangun partnership dapat dilakukan dengan cara mengembangkan kontrak jangka panjang dengan pemasok-pemasok tersebut sehingga pasokan dan kualitas dapat dipastikan untuk beberapa tahun ke depan. Strategi untuk barang pada kuadran leverage items adalah mendorong persaingan antar pemasok sehingga bisa didapatkan biaya yang paling ekonomis. Sedangkan strategi yang sesuai untuk item yang berada pada kuadran non-critical adalah menyederhanakan dan mengotomatisasikan proses pengadaan item-item tersebut. Hal ini dapat dilakukan dengan cara membuat katalog elektronik. Pemetaan menggunakan matriks ini dapat digunakan apabila terdapat item tambahan yang dibutuhkan untuk memproduksi disc'. Dengan pemetaan seperti ini diharapkan PT Inkoasku dapat merencanakan strategi yang tepat bagi setiap kategori item sehingga dapat tercapai pengadaan yang efisien dan berbiaya rendah. 


\begin{tabular}{|l|l|}
\hline $\begin{array}{l}\text { Bottleneck Items } \rightarrow \text { Ensure Supply } \\
\text { - Besi Baja }\end{array}$ & Strategic Items $\rightarrow$ Form Partnership \\
- Cat & \\
\hline $\begin{array}{l}\text { Non-critical Items } \rightarrow \text { Simplify and automate } \\
\text { - Packaging }\end{array}$ & $\begin{array}{l}\text { Leverage Items } \rightarrow \text { Exploit purchasing power and } \\
\text { minimize cost } \\
\text { Trucking }\end{array}$ \\
\hline
\end{tabular}

Gambar 4. Matriks Supply Kraljic untuk PT Inkoasku

Salah satu kemitraan strategis yang dapat dibangun terkhususnya untuk item-item strategis adalah Vendor Managed Inventory (VMI) dimana sistem persediaan akan dikelola oleh pemasok. Pemasok akan memutuskan tingkat persediaan yang sesuai dari masing-masing produk. VMI dilakukan dengan cara pemasok menerima data persediaan dan kebutuhan pelanggannya secara real-time sehingga pemasok dapat menentukan kuantitas dan waktu untuk memasok (Simchi-Levi et al. 2019). Keuntungan VMI adalah dapat mengurangi biaya sistem secara keseluruhan dan meningkatkan tingkat layanan. Namun dalam pelaksanaannya terdapat beberapa tantangan seperti membutuhkan sistem informasi yang canggih, membutuhkan sistem perencanaan dan data kendala produksi secara online yang akurat dan terintegrasi, serta mewajibkan para mitra untuk mengembangkan kepercayaan.

Selanjutnya adalah strategi pemilihan moda transportasi. Strategi yang diterapkan PT Inkoasku saat ini sudah sesuai dengan misi dan tujuan fungsional operasi dimana sistem operasi ini tidak sensitif terhadap waktu pengiriman melainkan sensitif terhadap harga. Dalam sistem operasi ini yang terpenting bukanlah barang diterima secepat mungkin melainkan biaya serendah mungkin dengan pengiriman sesuai dengan jadwal yang telah ditetapkan. Dengan menggunakan moda transportasi kapal dan truk, PT Inkoasku dapat mencapai biaya transportasi rendah dan pengiriman tepat waktu apabila pengiriman direncanakan sesuai dengan jadwal yang telah ditetapkan. Keputusan strategis rantai pasok seperti hubungan dengan pemasok, pemilihan pemasok, source decision dan information sharing berperan penting dalam mencapai keunggulan kompetitif perusahaan atau prioritas tujuan operasi yang telah ditetapkan oleh perusahaan (Joshi et al. 2013).

\section{Implikasi Manajerial}

Penelitian ini memberi masukan bahwa dalam rangka memproduksi baru yaitu disc' PT Inkoasku dapat memilih tipe proses batch. Dalam menerapkannya PT Inkoasku dapat membuat peta proses produksi dan peta layout fasilitas produksi. Selanjutnya PT Inkoasku juga dapat menghitung biaya kualitas untuk menunjang sistem perbaikan kualitas yang lebih formal sehingga peningkatan kualitas dan penurunan biaya dapat terukur lebih jelas. PT Inkoasku juga dapat melakukan identifikasi dan melakukan perbaikan terhadap waste atau kegiatan non-value added yang masih dilakukan pada aktivitas operasi. Untuk mengurangi kebutuhan tenaga kerja pada work center Plant Sunter, PT Inkoasku dapat melakukan otomatisasi pada mesin-mesin tersebut. Untuk melakukan otomatisasi PT Inkoasku perlu menganalisis dan melakukan identifikasi lebih lanjut pada mesin-mesin tersebut sehingga otomatisasi dapat memberikan dampak pengurangan biaya yang lebih optimal. Agar dapat menjadi produsen dengan biaya yang rendah, PT Inkoasku dapat menyimpan persediaan dengan tingkat yang rendah dengan menggunakan MRP dan lot for lot pada pengelolaan persediaan bahan baku. Hal ini dapat dilakukan karena data permintaan pelanggan yang cenderung pasti dan tingkat kinerja pemasok yang dapat diandalkan. Selain itu dalam pengelolaan spare part, PT Inkoasku dapat melihat data historis penggunaan sehingga dapat dicapai kuantitas dan biaya yang lebih ekonomis. Mengenai strategi rantai pasok, PT Inkoasku dapat melakukan pemetaan dengan matriks supply Kraljic untuk menetukan strategi pengadaan yang tepat bagi masing-masing bahan baku serta mulai membangun kepercayaan lebih lanjut dan urgensi dengan pemasok dan pelanggan untuk dapat menerapkan VendorManaged Inventory (VMI). 


\section{KESIMPULAN DAN SARAN}

\section{Kesimpulan}

Tujuan utama dari penelitian ini menyusun strategi operasi PT Inkoasku yang akan memproduksi disc' sebagai produk baru dengan menganalisis keadaan eksternal dan internal perusahaan terlebih dahulu. Penelitian ini mengungkapkan praktik yang telah diadopsi oleh PT Inkoasku dalam menjalankan operasi manufaktur komponen otomotif dan rekomendasi perbaikan bagi PT Inkoasku agar dapat memiliki keunggulan yang kompetitif. Strategi operasi dan rekomendasi perbaikan bagi PT Inkoasku dibangun berdasarkan penelitian-penelitian terdahulu, seperti framework penyusunan strategi operasi yang terdiri dari misi, tujuan dan keputusan strategis operasi (Schroeder dan Goldstein, 2021), empat aspek tujuan operasi: kualitas, delivery, biaya dan fleksibilitas (Schroeder dan Goldstein, 2021; Nurchayo dan Wibowo, 2015; Joshi et al. 2013), penyelerasan strategi bisnis perusahaan dengan strategi operasi (Okoshi et al. 2019; Filho et al. 2015), process profiling (Hill, 1995), framework LeanSix Sigma (Gomez Segura et al. 2020; Ben Ruben et al. 2017; Swarnakar dan Vinodh, 2016), pemetaan barang-barang yang di-outsource menggunakan Matriks Supply Kraljic (Kraljic, 1983) dan framework hubungan dengan pemasok (Simchi-Levi et al. 2019). Analisis eksternal dilakukan terhadap pelanggan dan pemasok. Bagi pelanggan aspek kualitas, delivery dan biaya merupakan hal yang penting dalam industri otomotif dan komponennya. Sedangkan bagi pemasok, aspek yang penting adalah harga dan hubungan dengan pemasok

Kondisi internal operasi PT Inkoasku diketahui berdasarkan analisis misi dan tujuan operasi serta sistem operasi PT Inkoasku yang meliputi lima aspek, yaitu proses, kualitas kapasitas, sediaan dan rantai pasok. Dalam analisis misi operasi, diketahui bahwa titik berat misi operasi PT Inkoasku adalah aspek biaya dan keselamatan kerja. Selanjutnya tujuan operasi PT Inkoasku dirumuskan ke dalam empat aspek, yaitu kualitas, delivery, biaya dan fleksibilitas (Schroeder dan Goldstein, 2021; Nurcahyo dan Wibowo, 2015; Joshi et al. 2013). Selain itu beberapa keputusan strategis yang telah dilakukan oleh PT Inkoasku dengan baik dan dapat terus dipertahankan seperti pembuatan dokumen kick-off untuk produk baru, pengelolaan finished goods menggunakan min-max policy, serta menggunakan truk dan kapal sebagai moda transportasi dan distribusi.
Selanjutnya terdapat juga beberapa hal yang sudah dilakukan oleh PT Inkoasku tetapi membutuhkan penyempurnaan seperti lean system yang perlu dikembangkan untuk memerhatikan jenis pemborosan lain dan sistem MRP yang dapat dikombinasikan dengan pemesanan lot for lot.

Berdasarkan analisis eksternal dan internal operasi maka misi operasi yang telah ditetapkan sebelumnya oleh PT Inkoasku yaitu "Menghasilkan produk dengan kualitas yang cukup, sesuai dengan yang dipersyaratkan pelanggan dengan biaya seefisien mungkin serta tetap mengutamakan keselamatan kerja" telah cukup baik dan dapat digunakan untuk tiga tahun mendatang. Selain itu tujuan dirumuskan dalam order qualifier dan order winner dimana delivery dan kualitas sebagai order qualifier dan harga sebagai order winner. Secara teoritis, tujuan operasi atau competitive priorities operasi ditentukan dengan mempertimbangkan faktor eksternal (faktor pasar dan industri) dan faktor internal (situasi dan konfigurasi simber daya yang dimiliki). Pada studi kasus ini, perusahaan menjadikan aspek biaya sebagai prioritas atau strategi kompetitif yang mencerminkan faktor pasar karena untuk dapat memenangkan persaingan perusahaan harus menjual produk dengan harga yang lebih rendah dari pada kompetitor. Oleh karena itu, rancangan strategi operasi yang telah dirumuskan tersebut diharapkan dapat memungkinkan perusahaan mencapai competitive priorities yang telah ditetapakan.

Keputusan-keputusan strategis dan implementasi strategi pada sistem operasi PT Inkoasku untuk memproduksi wheel dan disc' mencakup lima aspek, yaitu proses, kualitas, kapasitas, persediaan dan rantai pasok. Keputusan-keputusan strategis tersebut, antara lain (1) PT Inkoasku dapat memilih tipe proses batch dan menggunakan cellular manufacturing layout dalam menjalankan proses produksi. (2) PT Inkoasku perlu mempertahankan aktivitas pembuatan dokumen kick-off produk baru sebagai penetapan standar kualitas disc', menerapkan six sigma dan mengembangkan lean system. (3) PT Inkoasku perlu mengotomatisasi mesinmesin Sunter yang akan digunakan untuk produksi disc' dan menerapkan strategi wait and see (4) Keputusan persediaan yang digunakan dalam mengelola finished goods adalah kebijakan min-max, PT Inkoasku perlu mengoptimalkan sistem MRP yang ada dengan melakukan pemesanan lot for lot, serta mengelola persediaan consumable tidak rutin, menggunakan 
$Q$ system sehingga didapatkan kuantitas pemesanan ekonomis. (5) PT Inkoasku dapat menggunakan matriks supply Kraljic untuk menentukan strategi pengadaan yang tepat bagi setiap item. PT Inkoasku juga dapat menerapkan Vendor Managed Inventory (VMI), menggunakan truk dan kapal sebagai moda transportasi dan distribusi.

\section{Saran}

Strategi-strategi yang sudah dirancang sebelumnya dapat diterapkan dengan baik dan memberikan dampak yang baik apabila strategi tersebut mendapat dukungan dari berbagai pihak, baik dari pihak internal maupun pihak eksternal. Pihak manajemen perlu membangun kesadaran terlebih dahulu terkhususnya pada pihak internal dengan metode shop-floor communication (Alcaide-Muñoz, et al., 2018). Selain itu pelaksanaan implementasi strategi juga perlu dievalusi terus menerus secara berkala sehingga tingkat kemajuan dapat terukur dan mengetahui kesesuaian implementasi dengan tujuan. PT Inkoasku juga dapat mempertahankan dan terus mengoptimalkan hal yang sudah baik.

Penelitian selanjutnya dapat dilakukan untuk menentukan prioritas dari berbagai strategi operasi yang direkomendasikan oleh Chiarini (2019) menggunakan metodologi analytic hierarchy process (AHP). Selain itu penelitian sejenis juga dapat dilakukan pada perusahaan yang memproduksi komponen otomotif lain dan terhadap mitra rantai pasok lainnya dalam industri otomotif seperti pemasok bahan baku dan pabrik perakitan kendaraan bermotor. Dengan begitu strategi yang dirancang akan lebih komprehensif bagi setiap entitas dalam rantai pasok industri otomotif dan dapat berkontribusi pada pengembangan industri $4.0 \mathrm{di}$ industri otomotif.

\section{DAFTAR PUSTAKA}

Adane T, Nicolescu M. 2018. Towards a generic framework for the performance evaluation of manufacturing strategy: An innovative approach. Journal of Manufacturing and Materials Processing 2(2):23.

Alcaide-Muñoz C, Bello-Pintado A, Merino-Diaz de Cerio J. 2018. Manufacturing strategy process: the role of shop-floor communication. Management Decision 56(7):1581-1597.

Arana-Solares IA, et al. 2019. Contextual factors intervening in the manufacturing strategy and technology management-performance relationship. International Journal of Production Economics 207:81-95.

Ben Ruben R, Vinodh S, Asokan P. 2017. Implementation of Lean Six Sigma framework with environmental considerations in an Indian automotive component manufacturing firm: a case study. Production Planning and Control 28(15):1193-1211.

Chiarini A. 2019. Choosing action plans for strategic manufacturing objectives using AHP: Analysis of the path and pitfalls encountered - an exploratory case study. Journal of Manufacturing Technology Management 30(1):180-194.

Chatha KA, et al. 2018. Theoretical developments in empirical quantitative manufacturing strategy literature. International Journal of Operations and Production Management 38(1):183-210.

Chotipanich S, Issarasak S. 2017. A study of facility management operation strategy in shopping malls: Insights from 4 top-class shopping malls in Bangkok. Property Management 35(3):236253.

Datta PP, Roy R. 2011. Operations strategy for the effective delivery of integrated industrial productservice offerings: Two exploratory defence industry case studies. International Journal of Operations and Production Management 31(5):579-603.

Dwiyanti R, Hubeis M, Suprayitno G. 2017. Perumusan strategi operasi-produksi kosmetik (studi kasus PT ANI). MANAJEMEN IKM: Jurnal Manajemen Pengembangan Industri Kecil Menengah 12(1):35.

Filho AGA, Nogueira E, Bento PEG. 2015. Operations strategies of engine assembly plants in the Brazilian automotive industry. International Journal of Operations and Production Management 35(5):817-838.

[Gaikindo] Gabungan ndustri Kendaraan Bermotor Indonesia. 2019. Pasar Otomotif ASEAN: Thailand masih Perkasa, Indonesia Tempat Kedua.https://www.gaikindo.or.id/pasarotomotif-asean-thailand-masih-perkasaindonesia-tempat-kedua. [18 Januari 2021].

[Gaikindo] Gabungan Industri Kendaraan Bermotor Indonesia. 2020. Industri otomotif berdampak terhadap ekonomi nasional. https://www. gaikindo.or.id/industri-otomotif-berdampakterhadap-ekonomi-nasional. [19 Januari 2021]. 
Gomez Segura M, Oleghe O, Salonitis K. 2020. Analysis of lean manufacturing strategy using system dynamics modelling of a business model. International Journal of Lean Six Sigma 11(5):863-891.

Hill T. 1995. Manufacturing Strategy Text and Cases. Hampshire: MACMILLAN PRESS LTD.

Jagoda K, Kiridena S. 2015. Operations strategy processes and performance Insights from the contract apparel manufacturing industry. Journal of Manufacturing Technology Management 26(2):261-279.

Joshi D, et al. 2013. On supply chain competitiveness of Indian automotive component manufacturing industry. International Journal of Production Economics 143(1):151-161.

[Kemenperin] Kementrian Perindustrian. 2019. Kemenperin: industri tomotif dibidik jadi sektor primadona ekspor nasional. https://kemenperin. go.id/artikel/20965/Industri-Otomotif-DibidikJadi-Sektor-Primadona-Ekspor-Nasional. [18 Jan 2021].

Koch C, Bennett D, Markussen T. 2015. Operations strategy for maintaining competitiveness in a European automotive company. Di dalam: IAMOT 2015 - 24th International Association for Management of Technology Conference: Technology, Innovation and Management for Sustainable Growth; Cape Town, 8-11 Juni 2015. Proceedings June. hlm 2508-2532.

Kraljic P. 1983. Purchasing must become supply management. Harvard Business Review September-October:109-117.

Kulkarni S, Verma P, Mukundan R. 2019. Assessing manufacturing strategy definitions utilising textmining. International Journal of Production Research 57(14):4519-4546.

Macchi M, Savino M, Roda I. 2020. Analysing the support of sustainability within the manufacturing strategy through multiple perspectives of different business functions. Journal of Cleaner Production 258: 120771.

Nurcahyo R, Wibowo AD. 2015. Manufacturing capability, manufacturing strategy and performance of Indonesia automotive component manufacturer. Di dalam: $12^{\text {th }}$ Global Conference on Sustainable Manufacturing. Procedia CIRP 26. hlm 653-657.

Ocampo LA. 2019. Applying fuzzy AHP-TOPSIS technique in identifying the content strategy of sustainable manufacturing for food production. Environment, Development and Sustainability 21(5):2225-2251.

Okoshi CY, Pinheiro de Lima E, Gouvea Da Costa SE. 2019. Performance cause and effect studies: Analyzing high performance manufacturing companies. International Journal of Production Economics 210(January):27-41.

Reinhardt R, et al. 2017. A case study of sustainable manufacturing strategy: Comparative LCA of wheel hub engine for solar car application. 2017 International Conference on Research and Education in Mechatronics (REM):1-6.

Rinaldy D, Asmara A, Findi M. 2020. Strategi industri kecil menengah komponen otomotif (studi kasus PT PQR). Jurnal Aplikasi Bisnis dan Manajemen 6(1):37-49.

Schroeder RG, Goldstein SM, 2021. Operations Management in The Supply Chain: Decision and Cases Ed. ke-8. New York, NY: McGraw-Hill/ Irwin.

Scur G, Heinz G. 2016. A dimensão ambiental no contexto da estratégia de operações de montadoras do ABC paulista. Revista Brasileira de Gestao de Negocios 18(60):290-304.

Shavarini SK, et al. 2013. Operations strategy and business strategy alignment model (case of Iranian industries). International Journal of Operations $n s$ and Production Management 33(9):1108-1130.

Swarnakar V, Vinodh S. 2016. Deploying Lean Six Sigma framework in an automotive component manufacturing organization. International Journal of Lean Six Sigma 7(3): 267-293.

Xie L, Han H. 2020. Capacity sharing and capacity investment of environment-friendly manufacturing: Strategy selection and performance analysis. International Journal of Environmental Research and Public Health 17(16):1-20. 